\title{
Kinesics in EFL Language Teaching
}

\author{
I Putu Edi Sutrisna \\ STAHN Mpu Kuturan Singaraja \\ sutrisnaiputuedi@gmail.com
}

\begin{abstract}
This study was descriptive qualitative research to reveal the use of kinesics in EFL classrooms in STAHN Mpu Kuturan Singaraja. Specifically, the purposes of this study were: 1) to describe of how English lecturers perceive the kinesics in EFL communication; 2) to describe kinds of kinesics that the English lecturers use in their EFL classrooms; 3) to describe how the kinesics takes place in the EFL teaching and learning activities. The informants of the present study were three English lecturers in which the first informant was as the main informant and the two other informants were the secondary informants. The data were gathered through interviews using a validated interview guide. Data analysis was done by using Interactive Data Analysis Model proposed by Miles \& Huberman (1984). From the data analysis conducted, this present study found out that kinesics was always be found in the communication process in EFL teaching and learning activities as it was very beneficial to help the students in acquiring the target language. There were four types of kinesics dealing with the EFL teaching and learning process found. Those were gestures, head movements, eye contact, and facial expressions. Those basic aspects of kinesics are very useful and considered as an easier way to help the EFL students to understand the meaning of utterances containing some difficult vocabularies as well helped them to acquire the target language.
\end{abstract}

Keywords: EFL, gesture, kinesics, teaching

\section{Introduction}

Language is the foremost means of communication. Without a doubt, language plays a very important role in human life. This communication uses verbal and nonverbal codes in which naturally being used in social interaction. In everyday communication processes occurring in societies, spoken language takes a lead as the most powerful and useful means of communication used to deliver thoughts to others (Sutrisna, Ratminingsih, \& Artini, 2018). This spoken or verbal language tells the semantic meaning of the speakers in real-time when the communication occurs. However, this verbal or spoken language cannot tell fully about things that want to be delivered by the speakers; there is another thing that lies beneath what the one has said. Any messages hidden beneath the verbal or spoken language can be read through the "movement" of the speakers' body while they are speaking. It is called as kinesics, which is a study on the gestures, head movement, eye contact, and facial expressions that convey meaning in verbal communication (Kawamoto, 2007).

The word kinesics has a meaning of "movement" that is derived from the root word "kinesis". This kinesis term refers to the study of gestures, head movement, eye contact, and facial expressions in communication (Hans \& Hans, 2015). Meanwhile, according to Ahmad \& Sani (2012), kinesics focuses on how people communicate through body movement including gestures and eye 
contact. In addition, Littlejohn \& Foss (2009) stated that kinesics encompasses facial expressions, gestures, and body movements, which can be interpreted into several expressions expressing the thought, feelings, moods, intentions, and attitudes within the verbal language used in communication. According to those statements of the definition of kinesics stated by some experts, it can be concluded that kinesics is the interpretation of human body movements that can be taken as the symbolic metaphorical language used in the communication process in social interaction.

Unlike the words being vocalized in verbal or spoken language, kinesics cannot be simply interpreted in order to have the meanings implied. It is because according to Ahmad \& Sani (2012) kinesics in verbal communication may either be purposeful; messages which are intended to achieve a particular purpose, or incidental and unintended. Some kinesics are used as substitutes and complements for language, such as when being asked a question, we shake our head back and forth while saying "no". In other instances, we use gestures in place of words. A shrug of the shoulders, for instance, is used to indicate confusion or uncertainty.

This kinesics is interesting to be discussed more since many people seem do not fully understand what others want to express in communicating verbally. Most people tend to perceive the messages only by listening to the vocalized words only; they are lacking at realizing what may be implied on what the body movements of the speakers want to tell. Hans \& Hans (2015) agreed in this statement, in which in their study it was found that sometimes expressions and body language that expresses emotions better than words. In a line with that, Fabrigas \& Maniago (2018) also found out that nonverbal communication or kinesics, including gestures and other expressions, have a stronger meaning than verbal expressions when it is used as a science teaching strategy for indigenous learners. Meanwhile, Ahmad \& Zani (2012) found out that the most meaningful of conversational messages in students' points of view came from kinesics or nonverbal communication.

From those studies, it can be found that all of them vocalized similar results as the kinesics can deliver better messages in communication perceived by the students in general. However, those studies could not convey the true nature of the role of kinesics in EFL language teaching. Finding out the explanation of this issue on kinesics then will lead to EFL teaching and learning to have a deeper understanding of accepting what people would tell behind the words they speak. Therefore, this present study then aiming at describing the role of kinesics in EFL language teaching in STAHN Mpu Kuturan Singaraja. Then, specifically, the purposes of this study were: 1) to describe of how English lecturers perceive the kinesics in EFL 
communication; 2) to describe kinds of kinesics that the English lecturers use in their EFL classrooms; 3) to describe how the kinesics takes place in the EFL teaching and learning activities.

\section{Research Method}

This study used a descriptive qualitative research design to reveal the use of kinesics in EFL classrooms in STAHN Mpu Kuturan Singaraja. Creswell (2002) stated that this qualitative study, the researcher seeks a deep understanding of the views of one group or single individuals to obtain data of certain phenomenon. To ensure the validity of the data gathered, the data triangulation procedure was done by triangulating among different data sources to enhance the accuracy of the data collections (Creswell, 2002). Thus, this data triangulation was done by collecting data from the main informant and being checked with the data gathered from two secondary informants. The informants of the present study were three English lecturers, in which the first informant was as the main informant and the two other informants were the secondary informants. The data were gathered through interviews by using an interview guide that was already been validated by using the face validity method from two expert judges. As the experts gave their judgment, it was found that the interview guide was valid and readily be used as the research instrument. Data analysis was done by using Interactive Data Analysis Model proposed by Miles \& Huberman (1984). As be seen in Figure 1, there were several steps done in analyzing data in order to fulfill the objectives of this present research. Those steps in the data analysis were data collection, data display, data reduction, and drawing conclusions. Data collection was the process of gathering information from the informants. It was done by using interviews. Data reduction was the process of selecting, focusing, simplifying, and transforming the raw data collected from the data collection process. Data display was the next step done in which the data was organized in order to be readily described to answer the research questions. It was done in the form of a narrative description. Conclusion drawing was the last step done in which the researcher made a conclusion and verified the conclusion.

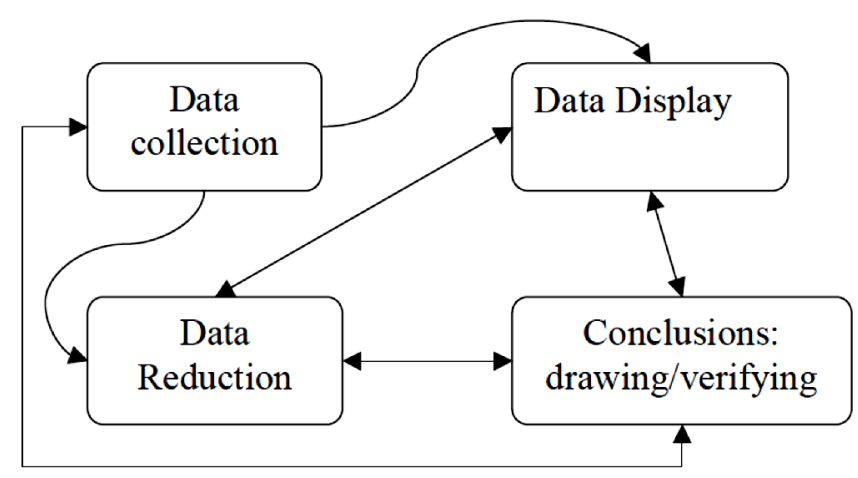

Figure 1. Interactive Data Analysis (Miles \& Huberman, 1984)

\section{Findings and Discussion}

A descriptive qualitative research design was carried out to seek a deeper understanding of the issue. After the data were obtained through the research method designed before, then the present 
study found that there were three main important findings to be discussed more. Firstly, the finding was on how EFL lecturers perceived the kinesics in communication; secondly, the finding was about the types of kinesics that the EFL lecturers used in their classrooms; and the last finding was on how kinesics being utilized in EFL teaching and learning activities.

From the interview done on the informants of the study, it was found that they already knew about the terms of kinesics as part of the communication process. They vocalized similar understanding toward kinesics, in which they said that kinesics is a part of the communication process where the verbal language is also affected by the body's movements of the speaker. They also said that kinesics as nonverbal communication is significant in the communications process. Interpreting body language is quite a complex process in which a single motion can have many different meanings in communication. For example is when people are talking, their facial expressions can deliver massages such as anger, disgust, fear, joy, sadness, and surprise. These English lecturers as the informants argued that this kinesics is always be found in the communication process in the EFL environment. Kinesics will be very beneficial if EFL people try to deliver their though by using English and try to understand what the native speakers have said during the conversations.
This finding on how the EFL lecturers in STAHN Mpu Kuturan Singaraja perceived kinesics in communication shows that it is correlated with the definitions given by some experts. In a line with this finding, Hans \& Hans (2015) stated that kinesics is a part of the communication process where gestures, head movement, eye contact, and facial expressions are involved. This present study's finding also supports the definition of kinesics given by Littlejohn \& Foss (2009) as well as Ahmad \& Sani (2012) where they have a similar definition towards kinesics that is communication process which is done through body movement including facial expressions, gestures, and body movements. However, the findings of this present study can give further insight into the point of view given by some experts mentioning about the definition of kinesics. This present study gives an additional term toward kinesics, especially in the EFL context in which it is found that kinesics or language through body movements always be used by EFL people when they are trying to deliver and get messages through English with native speakers.

From the interview done on the informants, it was found that they were aware of the use of kinesics in their teaching activities to foster the students' awareness in acquiring the target language. Therefore, it was found that there were several types of kinesics being used by the lecturers in the EFL classrooms. Those were gestures, head movements, eye 
contact, and facial expressions. This finding of the present study supports the other expert's point of view toward the types of kinesics in the communication process. Hans \& Hans (2015) explained that there are several types of kinesics emphasized in the communication process, those are gestures, head movements, eye contact, and facial expressions. The gesture is a kind of kinesics that is used to describe the speakers' body movements containing messages that want to be delivered through the communication process. There are three types of gestures, namely adaptors, emblems, and illustrators. According to Hans and Hans (2015), head movement is a type of kinesics dealing with the simple head movements that deliver meaning in nonverbal communication. In terms of head movements, a head nod is a universal sign of acknowledgment in cultures where the formal bow is no longer used as a greeting. In these cases, the head nod essentially serves as an abbreviated bow. Hans \& Hans (2015) also explained that eye contact can be used as a powerful means of communication. Eye contact serves several communicative functions ranging from regulating interaction to monitoring interaction to conveying information, to establishing interpersonal connections. In terms of regulating communication, we use eye contact to signal to others that we are ready to speak or we use it to cue others to speak. During an interaction, eye contact also changes as we shift from speaker to listener. Our eyes bring in the visual information we need to interpret people's movements, gestures, and eye contact. A speaker can use his or her eye contact to determine if an audience is engaged, confused, or bored and then adapt his or her message accordingly. Our eyes also send information to others. Making eye contact with others also communicates that we are paying attention and are interested in what another person is saying. According to Hans and Hans (2015), facial expression as a type of kinesics has the most expressive ways of telling the messages to others in the communication process.

However, the types of kinesics found in this present study were quite different with was proposed by Ekman \& Friesen (1969, as cited in Littlejohn \& Foss, 2009) which stated that there are five categories of kinesics or nonverbal behavior in communications. Those are: 1) Affect displays or emotional expressions. It basically occurs on the face and unconsciously displays and represents feelings and emotions. 2) Regulator. It maintains and organizes the flow interactions between communicated people. For example, approval can be expressed through head nods. 3) Adaptor. It helps to manage tension or stress. An example of alter-adaptors in interpersonal communication is touching others. Meanwhile, the example of selfadaptors can include several behaviors such as nail-biting, rubbing eyes, and fixing hairstyles. 4) Illustrator. It shows visually what is being described. Illustrators in communication include batons, which 
are used for emphasis; pictographs, which resemble their referents; kinetographs, which resemble bodily actions; ideographs, which portray the course of thought; deictic or pointing gestures; and spatial, which illustrate the rhythm of an event. 5) Emblem. It substitutes for words and therefore has conventionalized meaning.

Finally, the present study found interesting findings in how kinesics being utilized in EFL teaching and learning activities in STAHN Mpu Kuturan Singaraja. As the interview was done on the participants, it was found that kinesics was described as an easier way to help the EFL students to understand the meaning of utterances containing some difficult vocabularies. The lecturers in their EFL classes often used gestures, head movements, eye contact, and facial expressions. Based on the results of the interviews, it was found that gesture was the type kinesics that was used dominantly by the lecturers in their ESP classroom. During a teaching and learning process, the gesture was performed by the lecturers in order to give clues to the students about the things that the lecturers wanted to share. For example, the lecturers demonstrated something by moving their hands to make artificial acts or objects while they felt the students hard to understand what was being said by them. The result of this present study was also relevant to the study done by Nuhwan (2019) which found out that gesture was one of the kinesics aspects mostly used by the teacher in teaching, such as pointing out the student to answer the questions, lifting thumb as an appreciation when the student answer the question correctly, and waving hand to say no. So then, this present study can conclude that instead of translating the target language into the students' mother tongue, the lecturers tried to make them understand first by using gestures. The main reason for this was the lecturers tried to make the students pick up or acquire the target language; not just waiting for the translations. This point of view supports the idea expressed by Sutrisna, Ratminingsih, \& Artini (2018), where they argued that the students should acquire the target language by going for meaning first not drilling and memorization.

The next types of kinesics used by the lecturers in STAHN Mpu Kuturan Singaraja were head movements and eye contact. These two kinesics were not significantly used in their EFL classrooms. It was because head movements just are used as a signal of accepting and rejecting ideas or language expressions vocalized by the students. For example, when the students answer something correctly, the lecturers would nod their head and when the students answer it incorrectly, the lecturers would shake their head so that the students know that there was something incorrect in their language. In a line with head movements, eye contact was not significantly used in the EFL classroom to foster the acquisition of the target language. It was because 
this type of kinesics was used only for making the students focused on engaging themselves in the lesson given. Here, the eye contact from the lecturers made the students felt that they were always be engaging in the communication process while the lectures speaking in the front of the classroom.

The last type of kinesis found in EFL teaching at STAHN Mpu Kuturan Singaraja was facial expressions. According to Hans and Hans (2015), the facial expression is a type of kinesics that is categorized as the most expressive way of telling the messages to others in the communication process. This point of view had been confirmed by the finding of the present research, in which this present study found that facial expressions were very useful if it was used while using verbal language. It helped a lot in delivering messages that the one wanted to convey just by expressing these facial expressions. The EFL lecturers as the participants of this study argued that these facial expressions were significantly be used in EFL teaching and learning activities. By using the facial expressions, the students would be easier to get what the lecturers had said in front of the classroom. It was also found that several basic expressions which were commonly used when the participants taught their EFL students. Those facial expressions were expressions of happiness, anger, surprise, sadness, and uncertainty. This finding supports the basic and universal emotions human facial expressions can display facially which was proposed by Ahmad \& Zani (2012); those are anger, fear, disgust, surprise, happiness, and sadness. If we take a look at these facial expressions as a part of kinesics, we can argue that even without vocalizing any word, people can express their feelings as a part of the communication process just by looking at their facial expressions. If we see in Figure 1, Bailey (2018) illustrated basic facial expressions that are used in communication. It is seen that human expressions are quite unique and yet without any agreement, all of them know and understand every facial expression express by others. These facial expressions are recognizable by humans all over the world.

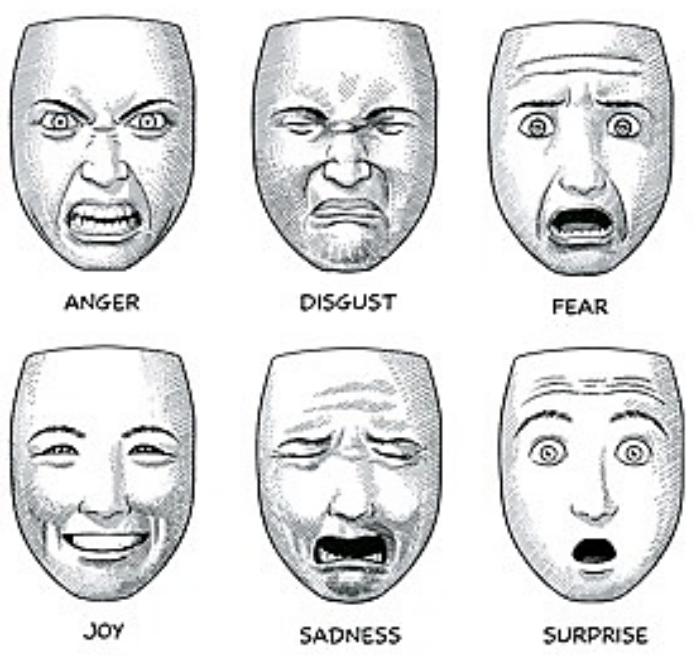

Figure 2. Basic Facial Expressions (Bailey, 2018)

Facial expressions are considered as the mirror of the mind (Rane, 2010). This is because many emotions are authentically expressed through the face. From Figure 2, it can be clearly seen that those facial 
expressions can be interpreted into the messages that the person wants to convey. If it is imagined that there is a person who says that she is happy but making a facial expression of "sadness" (see Fig. 2), we can tell that the word "happy" that she is saying does not imply the messages she wants to convey as a whole. There is more message behind the word "happy" that is spoken and the "sadness" facial expression that appears on her face. By understanding kinesics, in this kind of situation, it can be easy to have a deeper understanding of the communication process. Thus, the communication process will be successful and meaningful because both the speaker and the listener are perceiving the same messages.

There is a proverb saying "actions speak louder than words". From this proverb, then we can see the importance of nonverbal communication. Nonverbal communication is especially significant in intercultural situations. Interpreting body language is surprisingly complex because a single motion can have many different meanings. For instants, a frown shows negative feelings and a smile shows happy feelings. On top of that, the eye provides the most revealing facial expression such as anger, disgust, fear, joy, sadness, and surprise. How is the way to know when a person is happy even though she does not say that she is happy? It can be seen on the nonverbal cues such as a smile, open arms, widened eyes, and many more. Nonverbal cues are a way to express feelings without the usage of any verbal communication. Therefore, it is very possible that kinesics can tell an important message without even vocalized any single word. In this case, kinesics can greatly influence EFL teaching and learning activities. Kinesics takes place in the EFL teaching and learning activities by reinforcing the message that the lecturers in STAHN Mpu Kuturan Singaraja were trying to convey in order to persuade the listener to pick up the target language and understand what was being conveyed.

\section{Conclusion}

Non-verbal communication or kinesics is not only needed for daily communication; it also has an important role in the success of EFL language teaching. Based on the production of data on the use of nonverbal aspects of kinesics in EFL language teaching in STAHN Mpu Kuturan Singaraja, it was found that kinesics was significantly be used in EFL teaching and learning activities. Those types of kinesics used were gesture, head movement, eye contact, and facial expressions. By using the kinesics, the students would be easier to get what the lecturers had said in front of the classroom kinesics were described as the easier way to help the EFL students to understand the meaning of utterances containing some difficult vocabularies. During a teaching and learning process, kinesics was performed by the lecturers in order to give clues to the students about the things that the 
lecturers wanted to share. It was found that instead of translating the target language into the students' mother tongue, the lecturers tried to make them understand first by using gestures. The main reason for this was the lecturers tried to make the students pick up or acquire the target language; not just waiting for the translations. The proper understanding and knowledge of kinesics can further reinforce EFL language teaching, furthermore, in the future study, the researcher can explore more on connection or correlation of kinesics to the students' achievements in the EFL language classroom.

\section{Refferences}

Ahmad, S. S. \& Zani, R. D. (2012). Impact of kinesics on students' learning satisfaction. Elixir Mgmt. Arts 48. pp 9672-9675. Retrieved from:

https://www.elixirpublishers.com /articles/1351250783_48\%20(2012) \%209672-9675.pdf

Bailey, B. (2018). The Importance of Nonverbal Communication in Business and How Professors at the University of North Georgia Train Students on the Subject. Honors Theses. 33.

Creswell, John W. (2002). Educational research: planning, conducting, and evaluating quantitative and qualitative research - 4th ed. Boston: Pearson Education Inc.

Fabrigas, Y., \& Maniago, J. D. (2018). Kinesics as a Science Teaching Strategy for Indigenous Learners. International Journal of Contemporary Research and Review,
9(01).

https://doi.org/10.15520/ijcrr/2018 /9/01/409

Hans, A. \& Hans, E. (2015). Kinesics, haptics and proxemics: Aspects of non-verbal communication. IOSR Journal of Humanities and Social Science. 20(2). pp 47-52. Retrieved from:

http://www.iosrjournals.org/iosrjhss/papers/Vol20-issue2/Version4/H020244752.pdf

Kawamoto, F. (2007). Kinesic channel of nonverbal communication: barriers for the English-learning Japanese. 文京学院大学外国語学 部文京学院短期大学紀要, (6), 165173.

Littlejohn, S. W., \& Foss, K. A. (2009). Encyclopedia of communication theory (Vol. 1). Sage.

Miles, M. B. \& Huberman, A. M. (1984). Qualitative Data Analysis: A Sourcebook of New Methods. California; SAGE publications Inc. Nuhwan, R. (2019, April). THE USE OF NON-VERBAL ASPECTS OF KINESICS IN EFL CLASSROOM LANGUAGE. In Bogor English Student And Teacher (BEST) Conference (Vol. 1, pp. 19-25).

Rane, D. B. (2010). Effective Body Language for Organizational Success. IUP Journal of Soft Skills, $4(4), 17-26$

Sutrisna, I. P. E., Ratminingsih, N. M., \& Artini, L. P. (2018). Mall-Based English Instruction. JPI (Jurnal Pendidikan Indonesia), 7(1), 30-40. 